\title{
Frequent EPAS1/HIF2 $\alpha$ exons 9 and 12 mutations in non-familial pheochromocytoma
}

\author{
Jenny Welander ${ }^{1}$, Adam Andreasson ${ }^{2}$, Michael Brauckhoff ${ }^{3,4}$, Martin Bäckdahl ${ }^{5}$, \\ Catharina Larsson ${ }^{2}$, Oliver Gimm ${ }^{1,6,{ }^{*}}$ and Peter Söderkvist ${ }^{1, *}$ \\ 'Department of Clinical and Experimental Medicine, Faculty of Health Sciences, Linköping University, \\ Linköping SE-58185, Sweden \\ ${ }^{2}$ Department of Oncology-Pathology, Karolinska Institutet, CCK, Karolinska University Hospital, \\ Stockholm SE-17176, Sweden \\ ${ }^{3}$ Department of Surgery, Haukeland University Hospital, Bergen, Norway \\ ${ }^{4}$ Department of Clinical Science, University of Bergen, Bergen NO-5021, Norway \\ ${ }^{5}$ Department of Molecular Medicine and Surgery, Karolinska Institutet, Karolinska University Hospital, Stockholm \\ SE-17176, Sweden \\ ${ }^{6}$ Department of Surgery, County Council of Östergötland, Linköping SE-58185, Sweden \\ *(O Gimm and P Söderkvist contributed equally to this work)
}

Correspondence should be addressed to J Welander

Email

jenny.welander@liu.se

\begin{abstract}
Pheochromocytomas are neuroendocrine tumors arising from the adrenal medulla. While heritable mutations are frequently described, less is known about the genetics of sporadic pheochromocytoma. Mutations in genes involved in the cellular hypoxia response have been identified in tumors, and recently EPAS1, encoding HIF $2 \alpha$, has been revealed to be a new gene involved in the pathogenesis of pheochromocytoma and abdominal paraganglioma. The aim of this study was to further characterize EPAS1 alterations in non-familial pheochromocytomas. Tumor DNA from 42 adrenal pheochromocytoma cases with apparently sporadic presentation, without known hereditary mutations in predisposing genes, were analyzed for mutations in EPAS1 by sequencing of exons 9 and 12, which contain the two hydroxylation sites involved in HIF2 $\alpha$ degradation, and also exon 2 . In addition, the copy number at the EPAS1 locus as well as transcriptome-wide gene expression were studied by DNA and RNA microarray analyses, respectively. We identified six missense EPAS1 mutations, three in exon 9 and three in exon 12, in five of 42 pheochromocytomas (12\%). The mutations were both somatic and constitutional, and had no overlap in 11 cases (26\%) with somatic mutations in NF1 or RET. One sample had two different EPAS1 mutations, shown by cloning to occur in cis, possibly indicating a novel mechanism of HIF2 $\alpha$ stabilization through inactivation of both hydroxylation sites. One of the tumors with an EPAS1 mutation also had a gain in DNA copy number at the EPAS1 locus. All EPAS1-mutated tumors displayed a pseudo-hypoxic gene expression pattern, indicating an oncogenic role of the identified mutations.
\end{abstract}
Key Words
- EPAS1
- HIF2A
- pheochromocytoma
- mutation
- copy number
- gene expression

Endocrine-Related Cancer (2014) 21, 495-504 (c) 2014 Society for Endocrinology Printed in Great Britain
Published by Bioscientifica Ltd 


\section{Introduction}

Pheochromocytomas and abdominal paragangliomas are catecholamine-producing tumors derived from neuroendocrine chromaffin cells in the adrenal medulla or the extra-adrenal paraganglia. The tumors can be a manifestation of different hereditary tumor syndromes such as multiple endocrine neoplasia type 2 (MEN2), von Hippel-Lindau disease (VHL), neurofibromatosis type 1 (NF1) or familial pheochromocytoma-paraganglioma syndrome, which are caused by mutations in the genes RET, VHL, NF1, and SDHx respectively (Welander et al. 2011, Dahia 2014). In recent years, additional susceptibility genes for pheochromocytoma and paraganglioma have been discovered, including TMEM127 (Qin et al. 2010), MAX (Comino-Mendez et al. 2011), and $F H$ (Castro-Vega et al. 2014), and more rarely EGLN1 (Ladroue et al. 2008) and KIF1B (Schlisio et al. 2008). The majority of pheochromocytomas and paragangliomas are apparently sporadic, i.e. isolated and non-familial. Until recently, somatic mutations in many of the genes known to be associated with familial disease have been found only in a small proportion of the cases (Burnichon et al. 2011). This changed when somatic NF1 mutations were revealed in about $20-25 \%$ of sporadic pheochromocytomas (Burnichon et al. 2012, Welander et al. 2012), but still the majority of sporadic tumors remain unexplained. Studies of gene expression have revealed that pheochromocytomas and paragangliomas can be divided into two groups: $V H L$ - and $S D H x$-mutated tumors form one cluster (Cluster 1) with a hypoxia-related transcription signature, whereas RET/NF1/TMEM127/MAX-mutated tumors form another cluster (Cluster 2) and display transcription profiles characterized by the activation of kinase signaling pathways (Eisenhofer et al. 2004, Dahia et al. 2005, Dahia 2014). Sporadic tumors cluster into either of the two distinct groups, instead of forming clusters of their own, indicating that similar molecular mechanisms are involved.

Hypoxia-inducible factors (HIFs) are transcription factors involved in the cellular hypoxia response. Active HIF is a dimer composed of an $\alpha$ and a $\beta$ subunits. Whereas the $\beta$ subunit is stably expressed, the levels of the $\alpha$ subunits HIF $1 \alpha, \operatorname{HIF} 2 \alpha$, and HIF $3 \alpha$ are regulated by oxygen-dependent prolyl hydroxylases (Kaelin \& Ratcliffe 2008, Keith et al. 2012). Prolyl hydroxylation occurs at two specific proline residues in the oxygen-dependent degradation domain of HIF $\alpha$. This allows recognition and ubiquitination of the protein by the VHL tumor suppressor E3 ubiquitin ligase complex, thereby targeting it for proteasomal degradation. At low oxygen levels, the prolyl hydroxylation is reduced, resulting in stabilization of $\mathrm{HIF} \alpha$ and subsequent transcription of target genes involved in the hypoxia response, including metabolic changes and angiogenesis.

Mutations in VHL, EGLN1 (encoding the prolyl hydroxylase PHD2), and SDHx (encoding the subunits of succinate dehydrogenase) result in an accumulation of HIF $\alpha$ and thus a pseudo-hypoxic response, allowing activation of target genes proposed to contribute to chromaffin cell tumorigenesis (Maher 2013). Rarely, patients with polycythemia, a disease state characterized by an elevated concentration of red blood cells, have mutations in VHL, EGLN1 or in EPAS1, the gene encoding HIF2 $\alpha$ (Bento et al. 2014). Recently, somatic gain-offunction mutations in EPAS1 have been reported for the first time, to our knowledge, in paragangliomas associated with polycythemia (Zhuang et al. 2012), providing an additional link between polycythemia and neuroendocrine tumors and also supporting the hypothesis of pseudo-hypoxia as an important process in their development. A subsequent study revealed a germline EPAS1 mutation in a patient with polycythemia and paraganglioma (Lorenzo et al. 2013) which, just like the first mutations identified, was demonstrated to decrease ubiquitination and degradation, thereby increasing the stability of HIF2 $\alpha$. Subsequent studies identified somatic EPAS1 mutations in pheochromocytomas and paragangliomas also in the absence of polycythemia (Favier et al. 2012, Comino-Mendez et al. 2013, Toledo et al. 2013), and demonstrated that EPAS1 mutations promote tumor growth in mice (Toledo et al. 2013). So far, only a few cases of EPAS1 mutations have been reported in single sporadic pheochromocytomas/paragangliomas without polycythemia. Herein, we further investigated this new class of mutations by analyzing EPAS1 in a cohort of adrenal pheochromocytomas from patients with isolated, non-familial disease without polycythemia. In contrast to several previous studies focusing only on exon 12 , we sequenced both exons that cover the HIF $2 \alpha$ hydroxylation sites, as an instance of a gain-of-function mutation in exon 9 has been described (Lorenzo et al. 2013). As one mutation of unknown pathogenicity has been described in exon 2, adjacent to the DNA-binding domain (Toledo et al. 2013), this exon was also included. The findings were evaluated in view of copy number and gene expression results, clinical presentation and previously detected somatic mutations in these tumors.

Published by Bioscientifica Ltd. 


\section{Subjects and methods}

\section{Patients and biological samples}

The study included 42 primary adrenal pheochromocytomas from 42 patients presenting as sporadic without family history or syndromic features of the disease. None of the patients had polycythemia. Clinical data for the cohort have previously been published (Welander et al. 2012) and are presented in detail in Supplementary Table S1, see section on supplementary data given at the end of this article. Two patients had developed metastases during follow-up and were therefore classified as malignant according to the WHO criteria (Thompson et al. 2004), while 40 cases were without metastases. In addition, all cases were classified according to Armed Forces Institute of Pathology (AFIP) criteria (Lack 2007) (Supplementary Table S1). All samples were collected and studied with informed consent and approval from the local ethics committees. DNA was extracted from tissue and blood samples using the Maxwell 16 Tissue DNA Purification Kit (Promega) and the Maxwell 16 Blood DNA Purification Kit (Promega) respectively. RNA was extracted using the RNeasy Minikit (Qiagen), and cDNA synthesis was carried out with the Maxima First-Strand cDNA Synthesis Kit (Thermo Scientific, Waltham, MA, USA).

The tumors had previously been investigated for mutations in NF1, RET, VHL, SDHB, SDHD, and MAX genes, which revealed somatic NF1 mutations in ten samples and a somatic RET mutation in one sample (Welander et al. 2012). Two patients had non-synonymous single-nucleotide polymorphisms in SDHB (rs11203289) and SDHD (rs11214077) respectively. Subsequent mutation analysis of TMEM127 in all cases revealed a novel, constitutional missense sequence variant in one sample (c.10C > T, Supplementary Figure S1, see section on supplementary data given at the end of this article), which was predicted to be benign by the PolyPhen-2 algorithm (Adzhubei et al. 2010).

\section{Mutation screening and DNA copy number analysis of EPAS1}

Exons 2, 9, and 12 of EPAS1 were analyzed by direct Sanger sequencing of tumor DNA using previously described methodology (Welander et al. 2012) and primers as specified in Supplementary Table S2, see section on supplementary data given at the end of this article. Mutations were confirmed by sequencing of a second, independent PCR product from the same sample. When available, mutation analysis was also carried out on corresponding normal DNA from patients with mutations in the tumor DNA. In case 38, which had two different mutations, PCR amplification and cloning of EPAS1 cDNA into Escherichia coli were carried out to determine if the mutations occurred in cis or trans. A previously described cloning technique (Welander et al. 2012) was used, with the primers 5'-CGTCCTGAGTGAGATTGAGAAG-3' (in the exon 8-9 boundary) and 5'-CCAGTGGCTGGAAGATGTTT-3' (in exon 12). EPAS1 cDNA was then PCR amplified from each clone and sequenced.

The effects of missense mutations were predicted using PolyPhen-2 (Adzhubei et al. 2010). To study conservation of the affected residues, a multiple sequence alignment of the HIF $2 \alpha$ amino acid sequence between different species and a comparison with the human HIF1 $\alpha$ protein was carried out using the Clustal Omega algorithm (Sievers et al. 2011). The sequences used were $H I F 2 \alpha$ (EPAS1) from Homo sapiens (UniProt accession number Q99814), Mus musculus (P97481), Bos taurus (A5PJT1), Gallus gallus (Q9W7C6), and Danio rerio (B3DJD1), together with HIF1 $\alpha$ from $H$. sapiens (Q16665) for comparison.

Previously retrieved data from SNP microarray analysis (Affymetrix GeneChip Human Mapping 250K) of tumor DNA (Welander et al. 2012) was analyzed for copy number alterations in EPAS1 using Genotyping Console v. 4.0 (Affymetrix, Santa Clara, CA, USA).

\section{Gene expression analysis}

Total RNA was quantified with a NanoDrop-1000 spectrophotometer (Thermo Scientific) and $250 \mathrm{ng}$ were used for whole-transcriptome analysis with GeneChip Human Gene 1.0 ST arrays (Affymetrix), covering 28869 annotated genes with a median of 26 probes per gene. Two of the 42 sporadic tumor samples (number seven and 20) for which no RNA was available were excluded. Five hereditary tumors were used as controls (Supplementary Table S3, see section on supplementary data given at the end of this article): two with RET mutations, one with a NF1 mutation (Welander et al. 2012), one with a VHL mutation, and one with a SDHA mutation (Welander et al. 2013). Included samples had RNA integrity numbers (RIN) between 6.6 and 9.1 (mean 8.3) when analyzed using a 2100 Bioanalyzer system using the Eukaryote Total RNA Nano assay (Agilent Technologies, Santa Clara, CA, USA). Sense-strand cDNA was generated using the Ambion WT Expression Kit (Life Technologies) and then fragmented, labeled and hybridized to arrays in a GeneChip

Published by Bioscientifica Ltd. 
Hybridization Oven 640 using the GeneChip WT Terminal Labeling Kit (Affymetrix), all according to the protocols supplied by the manufacturers. The arrays were washed and stained in a GeneChip Fluidics Station 450 and scanned in a GeneChip Scanner 3000 7G (Affymetrix).

Microarray data files (CEL) were opened in Expression Console v. 1.3 (Affymetrix) and normalized using the robust multi-array average (RMA) algorithm. Normalized signal intensities for EPAS1, its target genes VEGFA, CCND1, EDN1, EPO, and SLC2A1 (Jochmanova et al. 2013), and the gene for phenylethanolamine $N$-methyltransferase (PNMT) were exported for separate statistical analysis as described below. The CEL files were also imported into GeneSpring GX v. 12.6 (Agilent Technologies) for transcriptome-wide statistical analysis and clustering. After RMA normalization, a quality filter was applied to remove probesets for which none of the 45 samples had signal intensity values greater than the 20th percentile of all signal intensity values of the sample. To test how the transcription profiles of EPAS1-mutated samples would cluster compared with genotypes with previously known expression patterns, a set of genes previously shown to separate the $S D H x, V H L$, and RET/NF1 groups was downloaded (Burnichon et al. 2011). These genes overlapped with 454 probesets that had passed the quality filter in our analysis, which was used to perform a hierarchical clustering with a Euclidean distance metric and Ward's linkage rule.

\section{Statistical analysis}

Gene expression levels of the seven candidate genes described above were compared between EPAS1-mutated and EPAS1-WT sporadic tumors using two-tailed Student's $t$-tests on the exported $\log 2$ signal values. After backtransformation $\left(2^{(\log 2 \text { signal })}\right)$, expression levels were normalized to the mean of the three hereditary Cluster 2 controls (samples eight, 12, and 14) for visualization in GraphPad Prism v.6.03 (GraphPad Software, La Jolla, CA, USA). Transcriptome-wide statistical analysis was carried out on all genes passing the quality filter in GeneSpring, in which genes with differential expression between EPAS1-mutated and EPAS1-WT sporadic tumors were identified by $t$-tests. The Benjamini-Hochberg method (Benjamini \& Hochberg 1995) was used to control for multiple testing. Genes were regarded as differentially expressed when they had a false discovery rate (FDR) $<0.05$ and an absolute fold change $>2$.

The clinical variables such as age, tumor size, and hormone levels were compared between cases with and without EPAS1 mutations using two-tailed Student's $t$-tests. Fisher's exact test was used to test for association with malignancy and gender. $P$ values $<0.05$ were regarded as significant.

\section{Results}

\section{Mutations in EPAS1}

Among 42 non-familial pheochromocytomas from 42 unrelated patients, five tumors harbored six missense mutations in EPAS1 (Table 1 and Fig. 1A), of which three were found in exon 9 and three in exon 12. No mutations were detected in exon 2. Two of the mutations were present in blood or normal tissue, whereas two were confirmed to be somatic, and two are unknown because neither blood nor non-tumor tissue was available (Fig. 1B). Two of the EPAS1 mutations occurred in the same patient, of which one was present in DNA from blood whereas the other was somatic. Molecular cloning showed that the two mutations occurred in cis (Supplementary Figure S2, see section on supplementary data given at the end of this article). All but one of the identified mutations occurred at highly conserved residues, and the three mutations in exon 12 occur in or in the vicinity of the primary hydroxylation site (Fig. 1C). PolyPhen analysis predicted four of the six amino acid substitutions to be damaging (Table 1).

Based on SNP microarray data, case 11, which also carried a mutation, had a gain (three copies) of the 2 p21 chromosomal region where EPAS1 is located (Supplementary Figure S3, see section on supplementary data given at the end of this article). The other 41 samples showed no copy number gain, but two samples without mutations (cases 2 and 34) had heterozygous loss of $2 p$, including EPAS1. No copy number alterations in the EPAS1 locus were found in 60 blood DNA samples from healthy controls analyzed by SNP microarrays. Previously known intronic or synonymous polymorphisms in EPAS1 (rs7557402, rs116510029, rs35606117, rs184760160, and rs41281469) were detected at the expected frequencies according to information in the Ensembl database.

\section{Gene expression patterns in EPAS1-mutated pheochromocytomas}

Tumors with EPAS1 mutations had a significantly higher gene expression of both EPAS1 $(P=0.0031)$ and its target gene VEGFA $(P=0.0039)$ than tumors without mutations (Fig. 2A). In addition, the EPAS1-mutated tumors had a very low expression of PNMT $(P<0.0001)$. Notably,

Published by Bioscientifica Ltd. 
Table 1 Details for apparently sporadic pheochromocytomas with mutation(s) in EPAS1/HIF2A

\begin{tabular}{|c|c|c|c|c|c|c|c|c|c|}
\hline $\begin{array}{l}\text { Case } \\
\text { number }\end{array}$ & Gender & Age & $\begin{array}{l}\text { Malignancy, } \\
\text { size }\end{array}$ & Exon & Mutation $^{a}$ & $\begin{array}{l}\text { Present in } \\
\text { normal DNA }\end{array}$ & $\begin{array}{l}\text { PolyPhen } \\
\text { prediction (score) }\end{array}$ & $\begin{array}{l}\text { EPAS1 } \\
\text { gain }\end{array}$ & $\begin{array}{c}\text { Biochemical } \\
\text { phenotype } \\
\text { NE/EPI/DA }\end{array}$ \\
\hline 11 & $\mathrm{~F}$ & 54 & $\begin{array}{l}\text { Benign, } \\
25 \mathrm{~mm}\end{array}$ & 12 & $\begin{array}{l}\text { c. } 1592 C>T^{c}, \\
\text { p.Pro531Leu }\end{array}$ & Unknown & Damaging (1.000) & Yes & $\mathrm{l} / \mathrm{N} / \mathrm{N}$ \\
\hline 19 & $\mathrm{~F}$ & 56 & $\begin{array}{l}\text { Benign, } \\
50 \mathrm{~mm}\end{array}$ & 9 & $\begin{array}{l}\text { c. } 1121 \mathrm{~T}>\mathrm{A}^{\mathrm{d}} \text {, } \\
\text { p.Phe374Tyr }\end{array}$ & Yes & Benign (0.074) & No & $\mathrm{I} / \mathrm{I} / \mathrm{N}$ \\
\hline 22 & $\mathrm{~F}$ & 61 & $\begin{array}{l}\text { Benign } \\
120 \mathrm{~mm}\end{array}$ & 9 & $\begin{array}{l}\text { c. } 1104 \mathrm{G}>\mathrm{A}, \\
\text { p.Met368Ile }\end{array}$ & Unknown & Benign (0.022) & No & $\mathrm{l} / \mathrm{N} / \mathrm{N}$ \\
\hline \multirow[t]{2}{*}{38} & M & 47 & $\begin{array}{l}\text { Benign, } \\
30 \mathrm{~mm}\end{array}$ & 9 & $\begin{array}{l}\text { c. } 1234 \mathrm{~T}>\mathrm{A}, \\
\text { p.lle412Asn }\end{array}$ & Yes & Damaging (0.999) & No & $\mathrm{I} / \mathrm{I} /-$ \\
\hline & & & & 12 & $\begin{array}{l}\text { c. } 1595 \mathrm{~A}>\mathrm{G}^{\mathrm{f}} \\
\text { p.Tyr532Cys }\end{array}$ & No & Damaging (1.000) & No & \\
\hline 52 & $\mathrm{~F}$ & 43 & $\begin{array}{l}\text { Benign, } \\
37 \mathrm{~mm}\end{array}$ & 12 & $\begin{array}{l}\text { c. } 1589 \mathrm{C}>\mathrm{A}, \\
\text { p.Ala530Glu }\end{array}$ & No & Damaging (1.000) & No & $\mathrm{l} / \mathrm{N} /-$ \\
\hline
\end{tabular}

F, female; M, male; EPI, epinephrine levels in plasma or urine before surgery; NE, norepinephrine levels in plasma or urine before surgery; DA, dopamine levels in urine before surgery; N, normal; I, increased; - , no value (further details can be found in Supplementary Table S1).

a Mutation nomenclature is based on the human EPAS1 sequence ENST00000263734 in the Ensembl database.

${ }^{\mathrm{b}}$ Non-tumor DNA was extracted from blood (samples 19 and 38) or adrenal cortex (sample 52).

'Previously reported in pheochromocytoma/paraganglioma (Comino-Mendez et al. 2013, Toledo et al. 2013).

dPreviously reported in pheochromocytoma/paraganglioma (Lorenzo et al. 2013).

e Malignant according to AFIP criteria (Lack 2007), local invasion.

fPreviously reported in pheochromocytoma/paraganglioma (Yang et al. 2013).

the target genes CCND1, EDN1, EPO, and SLC2A1 (Jochmanova et al. 2013), which have been frequently investigated by others (Zhuang et al. 2012, Lorenzo et al. 2013, Toledo et al. 2013), did not show any difference in expression in this study (Supplementary Figure S4, see section on supplementary data given at the end of this article). Possible explanations may include differences in detection methods or sampling, and/or that these genes, though clearly regulated by HIF2 $\alpha$ in some tissues, may have a more variable expression in the adrenal medulla. Six tumors without identified mutations but with high EPAS1 expression were sequenced for all the remaining exons of EPAS1 (Supplementary Table S2). No mutations were detected, but one case (case 6) had a missense polymorphism in exon 15 predicted to be benign (rs59901247, PolyPhen score 0.001, allele frequency 0.15 in Ensembl).

One of the recent large gene expression studies of pheochromocytomas and paragangliomas identified a set of genes that could separate tumors with $S D H x, V H L$, and RET/NF1 mutations by hierarchical gene expression clustering (Burnichon et al. 2011). To investigate how the gene expression profiles of EPAS1-mutated tumors would cluster compared with the previously known genotypes, we utilized the same set of genes (454 probesets) for hierarchical clustering of the present cohort. As expected, tumors with known somatic NF1 and RET mutations clustered together with hereditary NF1 and MEN2A cases (Fig. 2B). In contrast, all five tumors with EPAS1 mutations clustered together with the hereditary
VHL and SDH cases, in agreement with the hypothesis of a pseudo-hypoxic behavior. The sporadic tumors without identified mutations were distributed between the two main clusters. After transcriptome-wide comparison of sporadic tumors with and without EPAS1 mutations, 22 genes were significantly and more than twofold differentially expressed between the groups (Supplementary Table S4, see section on supplementary data given at the end of this article) after correction for multiple testing. Among those upregulated in EPAS1 cases were several genes involved in cell metabolism (COX4I2, NOX4, FOLH1, FOLH1B, COX17) and angiogenesis (KDR (VEGFR), ANGPT2). The most significantly upregulated gene, COX4I2, has previously been reported to be strongly upregulated in VHL/SDH-related pheochromocytomas (Favier et al. 2009) and another one, GNA14, has been recently observed by others to be significantly upregulated in EPAS1-mutated tumors (Comino-Mendez et al. 2013). Among the most downregulated genes are NCAM2 (a neural cell adhesion molecule, previously found to be upregulated in Cluster 2 tumors (Burnichon et al. 2011)), HCN1 (a cation channel contributing to neuron currents), and PNMT.

\section{Clinical presentation of EPAS1-mutated pheochromocytomas}

All five patients with EPAS1 mutation(s) had a single pheochromocytoma without recurrence or metastasis,

Published by Bioscientifica Ltd. 


$$
\begin{aligned}
& \text { c. } 1592 \mathrm{C}>\mathrm{T} \\
& \text { p.Pro531Leu }
\end{aligned}
$$

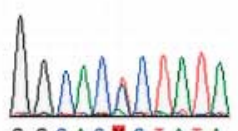

G GCACMCTATA

$$
\text { c. } 1121 \mathrm{~T}>\mathrm{A}
$$

p.Phe374Tyr

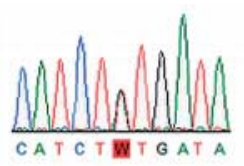

B

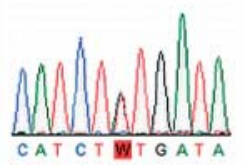

C. $1104 \mathrm{G}>\mathrm{A}$

p.Met368lle

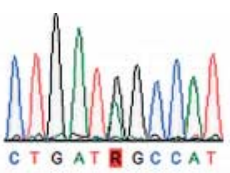

c. $1234 \mathrm{~T}>\mathrm{A}$

p.lle412Asn

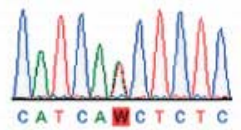

CAT CA WC T C T C

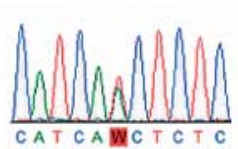

c. $1595 A>G$

p.Tyr532Cys

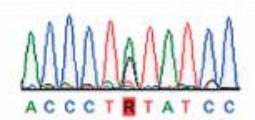

A C C C T B T A T C C

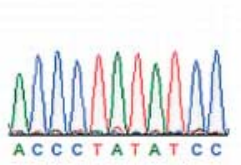

C. $1589 \mathrm{C}>\mathrm{A}$

p.Ala530Glu
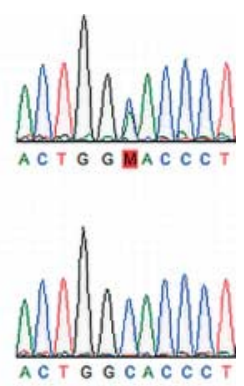

412

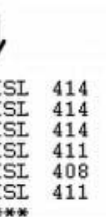

$530,531,532$

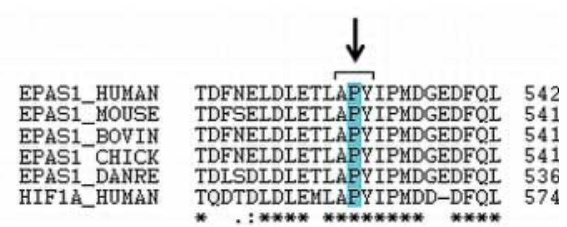

Figure 1

Mutations in EPAS1 identified in adrenal pheochromocytomas with sporadic presentation. (A) Mutations identified in tumor DNA. (B) Sequences from corresponding normal DNA (when available), showing that two of the mutations are constitutional. (C) Multiple sequence alignment of HIF $2 \alpha$

and none suffered from polycythemia. Re-evaluation of medical records showed that none of the patients had signs of hereditary tumor disease, but one presented with a ductal breast cancer in situ 4 years after the pheochromocytoma diagnosis (patient 22) and one suffered from sickle cell anemia (patient 52). Histopathologically, it can be noted that the tumor from case 19 showed slightly increased proliferation with 5\% Ki-67-positive cells, and case 22 presented local invasion in agreement with histopathological malignancy according to AFIP criteria (Lack 2007). Patients with EPAS1 mutations tended to be younger than those without EPAS1 mutations (mean $52.2 \pm 7.2$ vs $61.6 \pm 12.9$ years), but the difference was not statistically significant $(P=0.12)$. No associations were found between EPAS1 mutation status and tumor size, malignancy, or gender, but it can be noted that $80 \%$ of the patients with EPAS1 mutations were females, in agreement with the female dominance in the cases reported so far (Comino-Mendez et al. 2013, Pacak et al. 2013, Toledo et al. 2013). However, in another cohort where all susceptibility genes were investigated, EPAS1 mutations were detected in four males and one female (Welander et al. 2014). Data on hormone profiles were incomplete and did not allow any statistically significant conclusions. It can be noted that all five patients with
(EPAS1) from different species together with the human HIF1 $\alpha$ amino acid sequence. Prolyl hydroxylation occurs at Pro 405 and Pro531 in human HIF2 $\alpha$, indicated by the blue background. (*), identical residues; (:), conserved substitutions; (.), semi-conserved substitutions.

EPAS1 mutations were observed to display increased norepinephrine levels (Table 1 and Supplementary Table S1). In addition, these patients had normal or only slightly increased epinephrine levels (Table 1 and Supplementary Table S1), which is consistent with their low expression of PNMT (Fig. 2A).

None of the cases with EPAS1 mutation(s) had mutations in any of the tested susceptibility genes $N F 1$, $R E T, V H L, S D H B, S D H D$, or $M A X$, i.e. they were mutually exclusive with the somatic mutations identified in NF1 (24\%) and RET (2.4\%) in the cohort (Supplementary Table S1 and Figure S5, see section on supplementary data given at the end of this article). One case (number 19) had a constitutional, probably benign sequence variant in TMEM127 (Supplementary Figure S1, see section on supplementary data given at the end of this article).

\section{Discussion}

Mutation analysis of EPAS1 in 42 non-familial pheochromocytomas resulted in the identification of six different mutations, of which three have not been reported previously in pheochromocytoma or paraganglioma. The three mutations identified in exon 12 occur in or in close proximity to the primary hydroxylation site. Thus, they

Published by Bioscientifica Ltd 
A
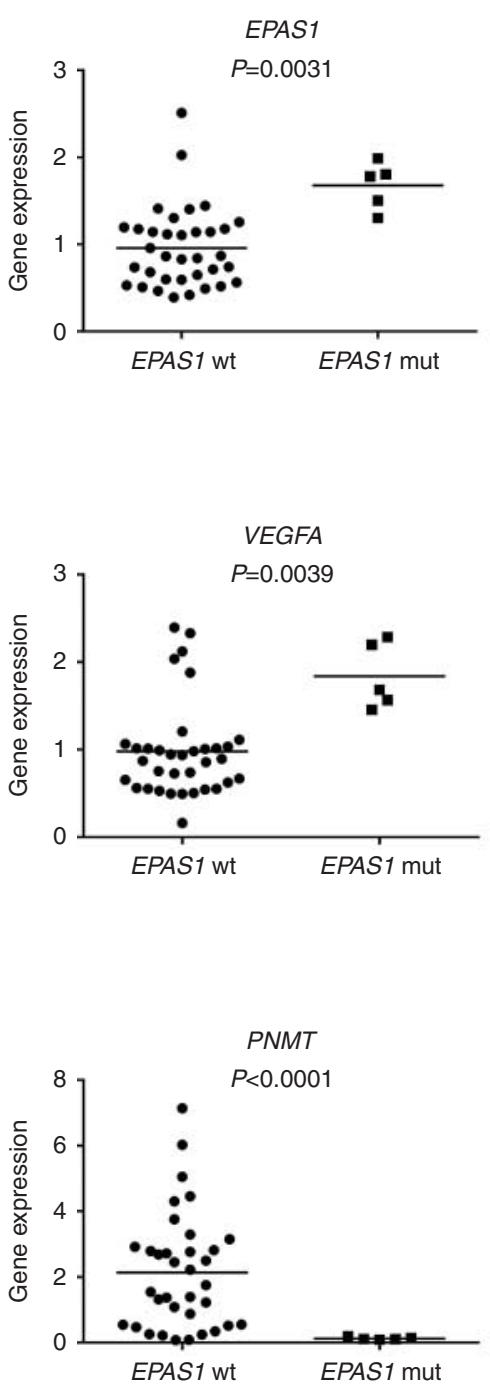

B

Tumors

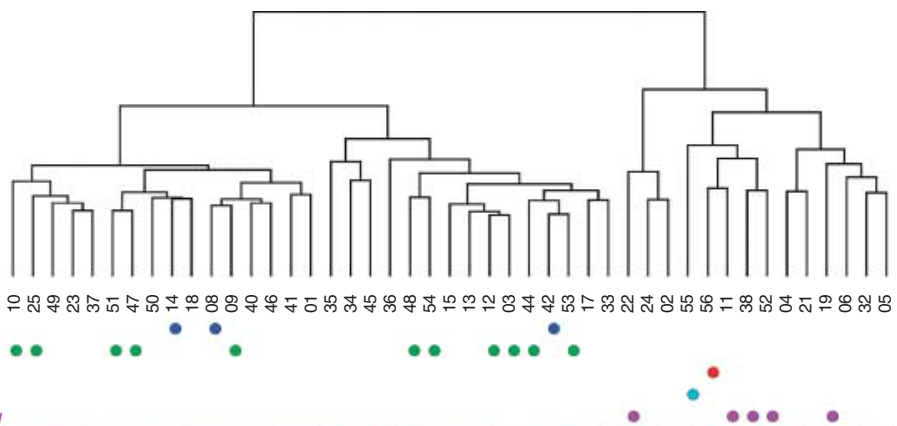

Figure 2

Gene expression in pheochromocytomas in relation to EPAS1 mutation status. (A) RNA levels of the genes EPAS1, VEGFA, and PNMT compared between sporadic pheochromocytomas with (EPAS1 mut, $n=5)$ and without (EPAS1 wt, $n=35$ ) EPAS1 mutations. The gene expression has been normalized to the mean value of cases with hereditary NF1 and MEN2A

are likely to affect the conformation of the hydroxylation domain and disrupt prolyl hydroxylation and degradation of HIF $2 \alpha$, as has previously been functionally demonstrated for this type of mutation (Zhuang et al. 2012, Toledo et al. 2013, Yang et al. 2013). The Phe374Tyr mutation in exon 9 was predicted to be non-pathogenic by PolyPhen and has been reported as a very rare polymorphism (rs150797491 with allele frequency defects. Horizontal bars represent mean values. (B) Hierarchical clustering of tumors based on RNA expression levels of 454 genes (implicated in pheochromocytoma subgroups (Burnichon et al. 2011)). High and low levels of expression are indicated by green and red colors respectively. Cases with mutations are highlighted below the dendrogram.

0.00092 in Ensembl), but, nevertheless, it has been demonstrated to be a gain-of-function mutation that decreases VHL protein binding and ubiquitination, increasing the stability of HIF2 $\alpha$ (Lorenzo et al. 2013). In both this and the previous study, the mutation was present in the constitutional DNA of a pheochromocytoma/paraganglioma patient. Met368Ile has also been reported as a rare polymorphism (rs61757375 with allele

Published by Bioscientifica Ltd. 
frequency 0.0014). This could be in agreement with the proposition that EPAS1 mutations are pheochromocyto$\mathrm{ma}$ /paraganglioma-promoting, but not sufficient for tumor development (Lorenzo et al. 2013), but further studies will be required to determine its pathogenicity. The novel Ile412Asn mutation occurs in a highly conserved residue close to the hydroxylation site and is bioinformatically predicted to be damaging.

Interestingly, two heterozygous EPAS1 mutations were identified in cis in the same tumor. It seems probable that the constitutional mutation, affecting an amino acid seven residues from the Pro405 hydroxylation site, is less severe than the somatic mutation close to the primary hydroxylation site Pro531 (Fig. 1C). Speculatively, the combination of the two may lead to an even higher stability of the HIF $2 \alpha$ protein than one mutation would cause alone, as previous results have indicated for the HIF1 $\alpha$ protein (Chan et al. 2005). One patient with an EPAS1 mutation also had copy number gain of the EPAS1 locus. The combination of activating mutations and copy number gain has previously been reported for EPAS1 (Comino-Mendez et al. 2013), as well as for other oncogenes (Modrek et al. 2009).

Our findings are in agreement with previous reports (Comino-Mendez et al. 2013, Toledo et al. 2013), and merging the present study with the two previous ones implies a total frequency of EPAS1 mutations of around $5.3 \%$ in sporadic tumors. In this cohort, the frequency of EPAS1 mutations was $11.9 \%$ or, more conservatively, $7.1 \%$ when not considering the two variants not immediately in the hydroxylation sites for which no functional studies have been performed. EPAS1 mutations were mutually exclusive with somatic mutations in other susceptibility genes in our cohort of pheochromocytomas, supporting an oncogenic role.

All tumors with EPAS1 mutations showed increased expression of the HIF $2 \alpha$ target gene VEGFA, which has also previously been shown to be upregulated in pheochromocytomas and paragangliomas with EPAS1 mutations (Zhuang et al. 2012, Lorenzo et al. 2013, Toledo et al. 2013). Notably, the tumors with mutations also had a higher expression of EPAS1 itself. The reason for this is not clear, as the mutations are thought to act at the protein level, but the same result has been observed previously (Comino-Mendez et al. 2013). We also show that the tumors with EPAS1 mutations have a very low expression of PNMT, encoding the enzyme PNMT which catalyzes the methylation of norepinephrine to form epinephrine. This is in agreement with the loss of PNMT expression in other Cluster 1 tumors as compared with Cluster 2 tumors, which have a high expression, resulting in high epinephrine levels (Eisenhofer et al. 2004). Furthermore, the five tumors with EPAS1 mutations clustered together with hereditary VHL and SDH cases, supporting the hypothesis that the mutations have a role in the disease by inducing a similar pseudo-hypoxic response. Interestingly, some sporadic tumors without any known mutations also clustered with the VHL/SDH/EPAS1 cases, some of which also had an increased expression of EPAS1. Those with high EPAS1 expression had the sequences of all EPAS1 exons determined, but no additional mutations were identified. This indicates that other, so far unknown, alterations of hypoxia response mechanisms may be involved in a subset of the sporadic tumors.

EPAS1 mutations have now been identified in association with a variety of phenotypes, including polycythemia without tumors (Percy et al. 2008), polycythemia in combination with single or multiple pheochromocytomas/ paragangliomas, and sometimes multiple somatostatinomas (Zhuang et al. 2012, Pacak et al. 2013, Taieb et al. 2013, Yang et al. 2013), as well as single or multiple pheochromocytomas/paragangliomas without polycythemia (Comino-Mendez et al. 2013, Toledo et al. 2013). Previous findings of EPAS1 mutations in different tumors from the same patient, but not in germline DNA, indicate that somatic EPAS1 mutations may occur in a cell during embryogenesis and predispose the affected tissues to tumor formation (Zhuang et al. 2012). However, it has been demonstrated that at least one reported case harbored a somatic mutation only in the tumor and not in adjacent normal tissue (Comino-Mendez et al. 2013). Possibly the variable phenotypes, constituted by different combinations of polycythemia and/or single or multiple tumors, may be directed by the specific time point of a somatic EPAS1 mutation, e.g. during early embryogenesis or later in life. Plausibly, the type of mutation as well as additional genetic, epigenetic, or environmental factors is also part of the explanation. In addition to somatic mutations, one case with an inherited mutation, identical to one of the constitutional mutations reported in this study, has been described previously (Lorenzo et al. 2013), but in contrast to the study by Lorenzo and colleagues, the patient reported here did not suffer from polycythemia. The penetrance of pheochromocytoma/paraganglioma for constitutional mutations is still unknown and will require further family studies, but the lack of family history of disease in the cases reported here supports an incomplete penetrance. It is also not possible to exclude the possibility that some of the variants do not play a pathogenic role in the clinical phenotype.

Published by Bioscientifica Ltd. 
In conclusion, we show that somatic as well as germline EPAS1 mutations are of importance in pheochromocytoma development. Our results indicate that mutations in both exon 9 and exon 12 of EPAS1 are frequent in isolated, non-familial pheochromocytomas, and that they are associated with a pseudo-hypoxiarelated gene expression pattern.

\section{Supplementary data}

This is linked to the online version of the paper at http://dx.doi.org/10.1530/ ERC-13-0384.

\section{Declaration of interest}

The authors declare that there is no conflict of interest that could be perceived as prejudicing the impartiality of the research reported.

\section{Funding}

This work was supported by grants from the University of Linköping, the Swedish Cancer Foundation, the Swedish Research Council, the Cancer Society in Stockholm, and StratCan at Karolinska Institutet.

\section{Acknowledgements}

The authors wish to thank Annette Molbaek for performing excellent laboratory RNA microarray analysis with great expertise, and Tobias Sivlér and Niyaz Hareni for other valuable technical support.

\section{References}

Adzhubei IA, Schmidt S, Peshkin L, Ramensky VE, Gerasimova A, Bork P, Kondrashov AS \& Sunyaev SR 2010 A method and server for predicting damaging missense mutations. Nature Methods 7 248-249. (doi:10.1038/nmeth0410-248)

Benjamini Y \& Hochberg Y 1995 Controlling the false discovery rate - a practical and powerful approach to multiple testing. Journal of the Royal Statistical Society. Series B (Methodological) 57 289-300.

Bento C, Percy MJ, Gardie B, Maia TM, van Wijk R, Perrotta S, Della Ragione F, Almeida H, Rossi C, Girodon F et al. 2014 Genetic basis of congenital erythrocytosis: mutation update and online databases. Human Mutation 35 15-26. (doi:10.1002/humu.22448)

Burnichon N, Vescovo L, Amar L, Libe R, de Reynies A, Venisse A, Jouanno E, Laurendeau I, Parfait B, Bertherat J et al. 2011 Integrative genomic analysis reveals somatic mutations in pheochromocytoma and paraganglioma. Human Molecular Genetics 20 3974-3985. (doi:10.1093/hmg/ddr324)

Burnichon N, Buffet A, Parfait B, Letouze E, Laurendeau I, Loriot C, Pasmant E, Abermil N, Valeyrie-Allanore L, Bertherat J et al. 2012 Somatic NF1 inactivation is a frequent event in sporadic pheochromocytoma. Human Molecular Genetics 21 5397-5405. (doi:10.1093/ hmg/dds374)

Castro-Vega LJ, Buffet A, De Cubas AA, Cascon A, Menara M, Khalifa E, Amar L, Azriel S, Bourdeau I, Chabre O et al. 2014 Germline mutations in $\mathrm{FH}$ confer predisposition to malignant pheochromocytomas and paragangliomas. Human Molecular Genetics 23 2440-2446. (doi:10.1093/hmg/ddt639)

Chan DA, Sutphin PD, Yen SE \& Giaccia AJ 2005 Coordinate regulation of the oxygen-dependent degradation domains of hypoxia-inducible

http://erc.endocrinology-journals.org DOI: $10.1530 / E R C-13-0384$ (c) 2014 Society for Endocrinology Printed in Great Britain factor 1 $\alpha$. Molecular and Cellular Biology 25 6415-6426. (doi:10.1128/ MCB.25.15.6415-6426.2005)

Comino-Mendez I, Gracia-Aznarez FJ, Schiavi F, Landa I, Leandro-Garcia LJ, Leton R, Honrado E, Ramos-Medina R, Caronia D, Pita G et al. 2011 Exome sequencing identifies MAX mutations as a cause of hereditary pheochromocytoma. Nature Genetics 43 663-667. (doi:10.1038/ng.861)

Comino-Mendez I, de Cubas AA, Bernal C, Alvarez-Escola C, Sanchez-Malo C, Ramirez-Tortosa CL, Pedrinaci S, Rapizzi E, Ercolino T, Bernini G et al. 2013 Tumoral EPAS1 (HIF2A) mutations explain sporadic pheochromocytoma and paraganglioma in the absence of erythrocytosis. Human Molecular Genetics 22 2169-2176. (doi:10.1093/hmg/ddt069)

Dahia PL 2014 Pheochromocytoma and paraganglioma pathogenesis: learning from genetic heterogeneity. Nature Reviews. Cancer 14 108-119. (doi:10.1038/nrc3648)

Dahia PL, Ross KN, Wright ME, Hayashida CY, Santagata S, Barontini M, Kung AL, Sanso G, Powers JF, Tischler AS et al. 2005 A HIF1 $\alpha$ regulatory loop links hypoxia and mitochondrial signals in pheochromocytomas. PLoS Genetics 1 72-80. (doi:10.1371/journal.pgen.0010008)

Eisenhofer G, Huynh TT, Pacak K, Brouwers FM, Walther MM, Linehan WM, Munson PJ, Mannelli M, Goldstein DS \& Elkahloun AG 2004 Distinct gene expression profiles in norepinephrine- and epinephrine-producing hereditary and sporadic pheochromocytomas: activation of hypoxia-driven angiogenic pathways in von Hippel-Lindau syndrome. Endocrine-Related Cancer 11 897-911. (doi:10.1677/erc.1.00838)

Favier J, Briere JJ, Burnichon N, Riviere J, Vescovo L, Benit P, Giscos-Douriez I, De Reynies A, Bertherat J, Badoual C et al. 2009 The Warburg effect is genetically determined in inherited pheochromocytomas. PLOS ONE 4 e7094. (doi:10.1371/journal.pone.0007094)

Favier J, Buffet A \& Gimenez-Roqueplo AP 2012 HIF2A mutations in paraganglioma with polycythemia. New England Journal of Medicine 367 2161-2162. (doi:10.1056/NEJMc1211953)

Jochmanova I, Yang C, Zhuang Z \& Pacak K 2013 Hypoxia-inducible factor signaling in pheochromocytoma: turning the rudder in the right direction. Journal of the National Cancer Institute 105 1270-1283. (doi:10.1093/jnci/djt201)

Kaelin WG Jr \& Ratcliffe PJ 2008 Oxygen sensing by metazoans: the central role of the HIF hydroxylase pathway. Molecular Cell $30393-402$. (doi:10.1016/j.molcel.2008.04.009)

Keith B, Johnson RS \& Simon MC 2012 HIF1 $\alpha$ and HIF2 $\alpha$ : sibling rivalry in hypoxic tumour growth and progression. Nature Reviews. Cancer 12 9-22. (doi:10.1038/nrc3183)

Lack EE 2007 Pheochromocytoma. In AFIP Atlas of Tumor Pathology: Tumors of the Adrenal Glands and Extraadrenal Paraganglia, pp 274-276. Washington, DC: American Registry of Pathology in collaboration with the Armed Forces Institute of Pathology (U.S.).

Ladroue C, Carcenac R, Leporrier M, Gad S, Le Hello C, Galateau-Salle F, Feunteun J, Pouyssegur J, Richard S \& Gardie B 2008 PHD2 mutation and congenital erythrocytosis with paraganglioma. New England Journal of Medicine 359 2685-2692. (doi:10.1056/NEJMoa0806277)

Lorenzo FR, Yang C, Ng Tang Fui M, Vankayalapati H, Zhuang Z, Huynh T, Grossmann M, Pacak K \& Prchal JT 2013 A novel EPAS1/HIF2A germline mutation in a congenital polycythemia with paraganglioma. Journal of Molecular Medicine 91 507-512. (doi:10.1007/s00109-012-0967-z)

Maher ER 2013 HIF2 and endocrine neoplasia: an evolving story. Endocrine-Related Cancer 20 C5-C7. (doi:10.1530/ERC-13-0146)

Modrek B, Ge L, Pandita A, Lin E, Mohan S, Yue P, Guerrero S, Lin WM, Pham T, Modrusan Z et al. 2009 Oncogenic activating mutations are associated with local copy gain. Molecular Cancer Research 7 1244-1252. (doi:10.1158/1541-7786.MCR-08-0532)

Pacak K, Jochmanova I, Prodanov T, Yang C, Merino MJ, Fojo T, Prchal JT, Tischler AS, Lechan RM \& Zhuang Z 2013 New syndrome of paraganglioma and somatostatinoma associated with polycythemia. Journal of Clinical Oncology 31 1690-1698. (doi:10.1200/JCO.2012.47.1912)

Percy MJ, Furlow PW, Lucas GS, Li X, Lappin TR, McMullin MF \& Lee FS 2008 A gain-of-function mutation in the HIF2A gene in familial 
erythrocytosis. New England Journal of Medicine 358 162-168. (doi:10.1056/NEJMoa073123)

Qin Y, Yao L, King EE, Buddavarapu K, Lenci RE, Chocron ES, Lechleiter JD, Sass M, Aronin N, Schiavi F et al. 2010 Germline mutations in TMEM127 confer susceptibility to pheochromocytoma. Nature Genetics $\mathbf{4 2}$ 229-233. (doi:10.1038/ng.533)

Schlisio S, Kenchappa RS, Vredeveld LC, George RE, Stewart R, Greulich H, Shahriari K, Nguyen NV, Pigny P, Dahia PL et al. 2008 The kinesin KIF1B $\beta$ acts downstream from EglN3 to induce apoptosis and is a potential 1p36 tumor suppressor. Genes and Development 22 884-893. (doi:10.1101/gad.1648608)

Sievers F, Wilm A, Dineen D, Gibson TJ, Karplus K, Li W, Lopez R, McWilliam H, Remmert M, Soding J et al. 2011 Fast scalable generation of high-quality protein multiple sequence alignments using Clustal Omega. Molecular Systems Biology 7 539. (doi:10.1038/msb.2011.75)

Taieb D, Yang C, Delenne B, Zhuang Z, Barlier A, Sebag F \& Pacak K 2013 First report of bilateral pheochromocytoma in the clinical spectrum of HIF2A-related polycythemia-paraganglioma syndrome. Journal of Clinical Endocrinology and Metabolism 98 E908-E913. (doi:10.1210/ jc.2013-1217)

Thompson LDR, Young WF (Jr.), Kawashima A, Komminoth P \& Tischler AS 2004 Malignant adrenal phaeochromocytoma. In World Health Organization Classification of Tumours: Pathology and Genetics of Tumours of Endocrine Organs, pp 147-150. Eds RA DeLellis, RV Lloyd, PU Heitz \& C Eng. Lyon: IARC Press.

Toledo RA, Qin Y, Srikantan S, Morales NP, Li Q, Deng Y, Kim SW, Pereira MA, Toledo SP, Su X et al. 2013 In vivo and in vitro oncogenic effects of HIF $2 A$ mutations in pheochromocytomas and paragangliomas. Endocrine-Related Cancer 20 349-359. (doi:10.1530/ERC-13-0101)
Welander J, Soderkvist P \& Gimm O 2011 Genetics and clinical characteristics of hereditary pheochromocytomas and paragangliomas. Endocrine-Related Cancer 18 R253-R276. (doi:10.1530/ERC-11-0170)

Welander J, Larsson C, Backdahl M, Hareni N, Sivler T, Brauckhoff M, Soderkvist P \& Gimm O 2012 Integrative genomics reveals frequent somatic NF1 mutations in sporadic pheochromocytomas. Human Molecular Genetics 21 5406-5416. (doi:10.1093/hmg/ dds402)

Welander J, Garvin S, Bohnmark R, Isaksson L, Wiseman RW, Soderkvist P \& Gimm O 2013 Germline SDHA mutation detected by next-generation sequencing in a young index patient with large paraganglioma. Journal of Clinical Endocrinology and Metabolism 98 E1379-E1380. (doi:10.1210/jc.2013-1963)

Welander J, Andreasson A, Juhlin CC, Wiseman RW, Backdahl M, Larsson C, Gimm O \& Soderkvist P 2014 Rare germline mutations identified by targeted next-generation sequencing of susceptibility genes in pheochromocytoma and paraganglioma. Journal of Clinical Endocrinology and Metabolism (In Press). (doi:10.1210/jc.2013-4375)

Yang C, Sun MG, Matro J, Huynh TT, Rahimpour S, Prchal JT, Lechan R, Lonser R, Pacak K \& Zhuang Z 2013 Novel HIF2A mutations disrupt oxygen sensing, leading to polycythemia, paragangliomas, and somatostatinomas. Blood 121 2563-2566. (doi:10.1182/blood2012-10-460972)

Zhuang Z, Yang C, Lorenzo F, Merino M, Fojo T, Kebebew E, Popovic V, Stratakis CA, Prchal JT \& Pacak K 2012 Somatic HIF2A gainof-function mutations in paraganglioma with polycythemia. New England Journal of Medicine 367 922-930. (doi:10.1056/ NEJMoa1205119)

Received in final form 8 April 2014

Accepted 9 April 2014

Made available online as an Accepted Preprint 16 April 2014
(C) 2014 Society for Endocrinology Printed in Great Britain
Published by Bioscientifica Ltd. 